\title{
Teoría de la autorreferencia mediática. Un balance crítico de los primeros estudios
}

\author{
Alejandro BARRANQUERO CARRETERO \\ Universidad Carlos III de Madrid \\ alejandrobarranquero@hotmail.com
}

Recibido: $26 / 12 / 2011$

Aceptado: 14/05/2012

\section{Resumen}

La autorreferencia mediática - o el relato constante de los medios acerca de sí mismos, la competencia o la comunicación en general -, se está convirtiendo en uno de los fenómenos más característicos del panorama cultural contemporáneo, hasta el punto de configurar una realidad mediática autónoma, artificial y sobredimensionada. Pero el discurso autorreferente pocas veces se emplea con fines autorreflexivos o desveladores del carácter mediado de los mensajes. En su lugar, figura como una estrategia más de autopromoción, con independencia del valor noticioso o interés público del acontecimiento mediático. De acuerdo a los estudios pioneros en la materia, centrados especialmente en prensa y televisión, este artículo se propone diseñar una cartografía inicial de estos trabajos, desde la perspectiva crítica y normativa que ha de guiar el periodismo y su compromiso con la verdad, la ecuanimidad y el servicio público.

Palabras clave: Autorreferencia, metacobertura, metacomunicación, discurso autorreferente

\section{Media Self-Reference Theory. A Critical State of Art of the Preliminary Research}

\begin{abstract}
Media self-reference - that is to say media stories about themselves, other media and communication in a broad sense - is becoming one of the main phenomena in the contemporary cultural landscape, to the point that it is creating an autonomous, artificial and overrated media reality. But self-referential discourse is scarcely used with an auto-reflexive objective or in order to reveal the mediated nature of messages. On the contrary, it is usually employed as an auto-promotional strategy, regardless of any news value or public interest conception. Based on the pioneering works on the issue-mainly focused on press and TV-, this paper aims at designing a preliminary framework of media self-reference theory to analyze the phenomenon from a critical and normative perspective, conceiving journalism from its commitment with truth, impartiality and public service.
\end{abstract}

Keywords: Auto-Reference, Meta-Coverage, Meta-Communication, Auto-Referential Discourse

\section{Referencia normalizada}

BARRANQUERO CARRETERO, Alejandro (2012): "Teoría de la autorreferencia mediática. Un balance crítico de los primeros estudios". Estudios sobre el mensaje periodístico. Vol. 18, núm. 1, págs.: 243-258. Madrid, Servicio de Publicaciones de la Universidad Complutense.

Sumario: 1. Comunicación autorreferente. La creación de una realidad mediática autónoma. 2. La autorreferencia en los medios y la cultura. 3. Concepto y tipos de autorreferencia mediática. 4. Balance de los estudios en España. 5. Conclusiones. 6. Referencias bibliográficas.

\section{Comunicación autorreferente. La creación de una realidad mediática autó- noma}

En la actualidad los medios de comunicación -y las distintas manifestaciones de la cultura en sentido amplio- se caracterizan por una acusada tendencia al discurso autorreferencial; esto es, sus mensajes ya no se limitan a informar acerca del entorno función referencial- o a reclamar respuestas al receptor -función apelativa, típica de la publicidad-, sino que muestran una disposición cada vez más marcada a hablar de 
sí mismos, de la competencia o de la propia comunicación en sí (LOZANO ET AL., 2011; PIÑUEL y GAITÁN, 2010) ${ }^{1}$. Parafraseando a Jakobson (1975, en ABRIL, 2005: 265-267), la función meta-lingüística, o aquella que remite a otro texto o código propio o ajeno, se ha convertido en una de las señas más identificativas de la cultura contemporánea $\mathrm{y}$, en concreto, de unos medios en exceso narcisistas (WILLIAMS, 2004), que, con relativa frecuencia, adoptan como referente de la comunicación a la comunicación misma hasta el punto de configurar una realidad mediática, artificial, autónoma y sobredimensionada, con amplias resonancias en los modos de conocer, sentir o imaginar: "Los receptores adaptan a sus discernimientos cotidianos las narrativas autorreferenciales y éstas terminan imponiéndose como un discurso hegemónico a propósito de la verdad en los temas de comunicación" (LozANo et al., 2011: 6-7).

Sin ser este un fenómeno por completo novedoso, los contenidos autorreferenciales parecen estar avanzando en progresión geométrica, al menos en la última década (SANTín, 2009). Y esto no es solo correlato de la matriz narcisista de la cultura postmoderna (IMBERT, 2011; LASCH, 1999; LIPOVETSKY, 2003), sino, y sobre todo, de un sistema mediático centrado en exceso en el rédito económico, que emplea lo autorreferencial como una forma más de promoción, con independencia de su valor noticioso o el interés público del acontecimiento. Por otro lado, si enmarcamos este fenómeno en una sociedad que se caracteriza, paradójicamente, por una búsqueda tan racional como efímera del conocimiento que resulta "en la increíble irracionalidad de las sobrecargas de información, la información errónea, la desinformación o la información descontrolada" (LASH, 2005: 23), detectamos en suma un territorio en exceso marcado por la infoxicación generalizada y la pérdida común de referentes.

Pese a su relevancia, las aproximaciones científicas a este nuevo objeto de estudio han sido, por el momento, escasas, sectoriales y en exceso centradas en la lógica de un solo medio (prensa). En este contexto, el trabajo que presentamos tiene por objeto plantear una primera cartografía nacional e internacional de unos estudios aún en fase embrionaria, dedicando especial atención a la prensa y la televisión y descartando, por el momento, el extenso panorama autorreferencial que inauguran nuevos soportes multimedia como Internet ${ }^{2}$.

La finalidad es interpelar a las ciencias de la comunicación a seguir profundizando en este vasto territorio sobre la base de los estudios ya existentes y desde marcos teórico-metodológicos compartidos. Se propone asimismo un enfoque interdisciplinar y multiprogramático amplio que ayude a dar cuenta de los frecuentes trasvases y diá-

1 Este estudio se enmarca dentro de las líneas de investigación del Grupo Mediación Dialéctica de la Comunicación Social-MDCS de la Universidad Complutense de Madrid y en concreto del proyecto $\mathrm{I}+\mathrm{D}+\mathrm{i}$ titulado El discurso hegemónico a propósito de la verdad y de la comunicación: lo que dicen los MCM sobre la Comunicación Social (Ref. SEJ2007-62202SOCI), dirigidos por José Luis Piñuel Raigada.

2 Aunque, en cierto sentido, apelemos a ella en el siguiente epígrafe, descartamos evaluar lo que Juan Carlos Miguel De Bustos (2000: 115-150) denomina la autorreferencia cruzada, o "cuando los contenidos de una industria cultural determinada sirven para elaborar contenidos de otra industria, como las revistas que hablan de libros, de cine o de música". 
logos entre medios, tecnologías y culturas, así como de las múltiples dimensiones o implicaciones últimas de este fenómeno. Con este esfuerzo estaremos dando los primeros pasos hacia la elaboración de una teoría de la comunicación autorreferencial que contribuya a una mejor comprensión de estos discursos, de sus valores y funcionalidades, así como sus efectos sobre la práctica del periodismo, la construcción de la agenda social o la definición misma de la realidad.

\section{La autorreferencia en los medios y la cultura}

Lo autorreferencial es una obligada estación de paso a la hora de interpretar los mensajes y signos culturales del presente. Un rápido vistazo a la actualidad nos permite observar ejemplos en todos los ámbitos, no sólo en los medios tradicionales -prensa, radio o televisión-, sino, en un sentido amplio, en las nuevas manifestaciones infotecnológicas -social media, ciberperiodismo, blogs, redes sociales- o en los diversos repertorios de la cultura: cine, literatura, teatro, música, artes plásticas, moda, videojuegos, etc. Así, junto a anuncios que han dejado de hablar de los productos y se basan en alusiones a otros anuncios (HUICI, 1991), la autorreferencia es una de las prácticas más habituales en la cobertura de la política, especialmente en época de campaña electoral, en la que los medios suelen dedicar un rol activo al desentrañar las estrategias de marketing de los diferentes candidatos o a comentar in extenso la celebración de debates electorales o la publicación de sondeos sobre intención de voto.

La autorreferencia es asimismo visible en el día a día de los periódicos, en las falsas noticias que acompañan al lanzamiento de una nueva promoción -ej. coleccionables, regalos-, o en las cada vez más insistentes noticias en torno al devenir de una publicación -ej. índices de audiencia, balances de negocio- o de su grupo empresarial -ej. El País informando acerca de las actividades de La Ser o el Grupo Prisa-. Por su parte, la televisión constituye un amplio territorio de autorreferencialidad. Muestra de ello son las telepromociones y los programas contenedores en los que se intercalan alusiones constantes a otros programas de la cadena, los productos basados en aludir a emisiones propias o ajenas -ej. formatos de zapeo- o las cámaras voyeur revelan sin pudor los bastidores de la realización.

No andaba equivocado Umberto ECO (1986) cuando señaló que el narcisismo del medio es una de las características fundamentales de una neo-televisión, que ha dejado de ser ventana abierta a la realidad para hablar cada vez más de sí misma, una línea de trabajo que ya anticipara el propio Raymond Williams (DE LARA, Rodríguez FERRÁNDIZ y SÁNCHEZ OLMOS, 2011: 7-8), y que ha tenido bastante continuidad en reflexiones acerca de la neo-, meta- o post-televisión (CARLón, 2006; GONZÁLEZ Requena, 1989; Imbert, 2003, 2011; LóPez Font y GonZÁlez OÑate, 2005; MisSIKA, 2006; OLSON, 1987).

Ya en un tiempo más reciente, la propia Internet se ha revelado como un escenario extenso de autorreferencias, sobre todo debido a su propio carácter de metamedio (MANOVICH, 2005), que subsume técnicas o discursos propios de medios escritos o audiovisuales. Así, por ejemplo, las redes sociales-Facebook, Twitter-se configuran como espacios de construcción sentido cifrados en conversaciones interminables sobre los tweets o posts de otros internautas o acerca de la información publicada por otros medios. 
Tal vez el escenario donde más se ha analizado la presencia de autorreferencia es en las múltiples expresiones de la cultura. En este sentido, son abundantes los estudios sobre meta-ficción, o literatura basada en el propio escritor o en proceso de la escritura (DotRAs, 1994; JAY, 1984), las músicas que samplean y resignifican otras músicas pasadas (DunNe, 1992; Puig y Talens, 1999), el cine en, desde y sobre el cine (PÉrez Bowie, 2006; StAm, 1992), o unas artes ensimismadas que desde las Vanguardias no han dejado de retratarse a sí mismas, alejándose de toda representación del mundo inmediato.

La autorreferencialidad ha sido interpretada desde diversos ángulos, en especial a partir de una fecunda línea de investigación abierta, entre otros, por Michel FoUCAULT, que, en su celebrado Las palabras y las cosas (1966), apuntó al abandono de la representación -y el refugio en la autorreferencia, añadiríamos- como uno de los elementos distintivos de la crisis de una modernidad basada hasta entonces en certezas y racionalidades (NöTH, 2001, p. 365). Desde entonces, los debates en el ámbito en el campo de las ciencias sociales han variado desde las posiciones post-modernas más escépticas, o apocalípticas -en terminología de ECO (1975)-, que vaticinan una pérdida gradual de los significados en un mundo de simulacros (BAUDRILLARD, 1984, 1996; VIRILIO, 1988), hasta posturas como las de Niklas LuHMANN, que desde una perspectiva más optimista o integrada, interpreta la autorreferencia como un elemento consustancial a la propia lógica de los medios.

En la primera línea, el pensamiento postmoderno resulta iluminador al insistir en que el poder actual de los media no está tan ligado a su contenido -ideológico- como a su código mismo, convertido en un universo autónomo de intercambios referenciales que abandona el terreno fáctico de lo real para adentrarse en una hiperrealidad en la que los límites entre los hechos y la simulación se vuelven difusos, cuando no aparecen asociados a riesgos imprevisibles (BECK, 2006): "La indiferenciación afortunada de lo verdadero y lo falso, de lo real y lo irreal, cede ante el simulacro, que, en cambio, consagra la indiferenciación desafortunada de lo verdadero y lo falso, de lo real y sus signos, el destino desafortunado, necesariamente desafortunado, del sentido en nuestra cultura" (BAUDRILLARD, 1996: 11).

Por otra parte, desde la sistémica, el sociólogo alemán LuHMANN señala que los medios constituyen un sistema autorreferencial relativamente cerrado que no está tan determinado por los valores externos como la verdad, la objetividad o la búsqueda del conocimiento como por criterios que derivan de su propia continuidad en el tiempo, y que se mueve en una sutil dialéctica en la que la que lo autorrepresentado (self-reference) prevalece sobre la representación misma del entorno o el otro (other-reference): "Las comunicaciones continuarán durante la siguiente hora o el día siguiente. Cada programa porta la promesa de otro programa. Nunca se trata de representar simplemente el mundo en un momento dado" (LuHMANN, 2000: 11). Este hecho es intrínseco a la propia ontología de los media, que, con su labor de selección en clave autorreferente, contribuyen, no obstante, a reducir la complejidad del mundo, hacerla inteligible al resto de sistemas sociales -político, judicial, económico-, garantizando con ello su equilibrio y supervivencia. 


\section{Concepto y tipos de autorreferencia mediática}

La autorreferencia ha sido definida desde diferentes perspectivas y enfoques teóricometodológicos. Stricto sensu, comprende cualquier discurso mediático que alude a la propia actividad de la comunicación, en el que emisor y referente, enunciador y enunciado, coinciden en mayor o menor grado (De LARA ET AL., 2011; NÖTH Y BiSHARA, 2007: 5-6; PiÑUel y GaITÁn, 2010; SANTín, 2009: 17), y en el que se enmarcan relatos de actores, prácticas, normativas, rituales, productos y organizaciones mediáticas, así como de otros sectores profesionales del ámbito de la comunicación: relaciones públicas, marketing político, comunicación organizacional, directores de comunicación, etc. (ESSER, 2009)3.

Lo autorreferencial puede ser entendido asimismo como un criterio más de noticiabilidad (news value) en una sociedad paulatinamente mediada, o en la expresión crítica de Mauro Wolf: “ejemplo de valores noticia que fijan la mirada en sí mismos, llevando a la exasperación la autorreferencialidad del periodismo" (WOLF, 1997: 914). Para otros autores su importancia como tema (issue) configura una agenda mediática propia y sobredimensionada, que determina o incluso sustituye a la agenda pública (PIÑUel y GAITÁn, 2010) y que en realidad "sólo afecta a sus propietarios o a sus rivales para convertirse en objeto de interés general" (BARRERA, 1999: 209).

Más común aún es la visión adoptada por algunos análisis pioneros en el ámbito anglosajón, que enmarcan lo autorreferencial dentro de los estudios de enfoque, tematización o encuadre mediático (framing), un programa de investigación que subraya la existencia de patrones de cognición e interpretación a partir de los cuales se selecciona y se da preeminencia a unos aspectos de la realidad sobre otros (ENTMAN, 1993). La autorreferencia o meta-cobertura (meta-coverage) ${ }^{4}$ constituye un nuevo frame metacomunicacional, que enfatiza, como su propio nombre indica, en el acontecer de los medios y en la comunicación en un sentido más amplio. Este encuadre ha sido examinado en especial dentro del campo de la comunicación política y electorals, en el que se señala que desde la década de los 90 del pasado siglo los medios tienden a percibirse y desempeñarse cada vez más como sujetos activos de primer orden y, en este volver el foco hacia adentro -turning the spotlight inward- (JOHNSON et al., 1996),

3 No profundizamos, más que tomando algunas referencias, en interesantes estudios en el campo de la lingüística, la lógica o la semiótica, como el editado por NöTH y BISHARA (2007), entre otros.

4 El concepto de metacobertura (meta-coverage) fue acuñado por el investigador estadounidense Todd GiTLIN (1991) y ha adquirido importantes desarrollos en el campo del frame gracias a los estudios de Matthew KERBEL, Frank EsSER, Paul D'ANGELO y sus colaboradores. Conviene asimismo llamar la atención sobre otras definiciones: noticias de procesos autoreferenciales (self-referential process news) (KERBEL, 1998), noticias sobre procesos mediáticos (media process news) (KerBel, ApEe y Ross, 2000; DEACON et al., 2011), historias sobre medios (stories about media) (JoHNSON et al., 1996) o historias mediáticas (media stories) (STEMPEL y WiNDHAUSER, 1991).

5 Los estudios sobre el frame metacomunicacional no se limitan a la cobertura de elecciones. También se han aplicado, entre otros, al tratamiento informativo de crisis, conflictos y guerras (ESSER, 2009; DiMITROVA et al., 2005), a programas de parodia política (BAYM, 2005; BREWER y MARQUARDT, 2007) o entretenimiento (WILliams, 2009). 
se alejan progresivamente de su función tradicional de meros intérpretes del acontecer para insertar "su propia construcción de los eventos y temas entre los candidatos y los votantes" (LichTER et al., 1999: 363-364): "Los periodistas, que en tiempos pasados eran comunicadores pasivos de la información sobre las figuras políticas, han emergido de forma creciente desde el fondo a hablar de ellos mismos -sus observaciones políticas, sus experiencias en la cobertura de los políticos, sus pensamientos sobre cómo se deben elaborar las noticias" (KERBEL, 1999: 83)

Los estudios pioneros de Frank Esser y Paul D'ANGelo $(2003,2006)$ advierten que el frame metacomunicacional está estrechamente relacionado con la emergencia de un tercer actor en el proceso de la comunicación política: los asesores de campaña -political public relations y spin doctors-. La presencia de estos agentes provoca que sea necesario distinguir entre dos dimensiones distintas dentro de este encuadre: las comunicaciones autorreflexivas acerca del papel o el impacto de los medios como actores o fuentes autónomas en los relatos políticos (press frame) y aquellas que atañen a la interacción entre candidatos políticos y asesores -el backstage de la campaña y las estrategias de marketing político- en su intento de influir sobre periodistas y votantes (publicity frame). Interpretando libremente la tipología de los autores, podríamos extrapolar estas nociones a otros ámbitos de especialización periodística como la economía o la cultura, en los que también existen intermediarios: relaciones públicas de las empresas, representantes del mundo de la cultura, etc. En estos casos, y aunque tal vez menos usuales, también se perciben frames meta-comunicacionales que inciden bien en la autoevaluación del propio rol de los medios -ej. artículos de opinión sobre los efectos inhibidores de la difusión mediática del miedo, si seguimos el modelo de la propaganda de CHOMSKY y HERMAN (2000)-, bien en las estrategias publicitarias o propagandísticas de otros actores comunicacionales -ej. piezas informativas que describen el patio trasero de un estreno teatral-.

En este proceso de categorización interesa distinguir igualmente entre diversos grados de referencia dentro de un mismo grupo mediático: autorreferencia absoluta (o en sentido explícito), cuando el propio medio se refiere a sí mismo, a su empresa editora o a sus diversos suplementos o productos, de modo que emisor y referente coinciden por completo; o autorreferencia relativa (o en sentido implícito), de menor grado, cuando un soporte o medio determinado se refiere a otro soporte o medio de su mismo grupo empresarial - ej. una noticia de la Cadena Ser publicada en El País(SANTín, 2009: 22) .

${ }^{6}$ Si bien la autorreferencia en el campo de la comunicación política no es en sí negativa, sobre todo cuando contribuye a educar a la ciudadanía acerca de la conformación mediática de cualquier campaña, el problema llega cuando su énfasis (salience) se cifra en clave de carrera o competición por unos votos -o horserace journalism en terminología de GITLIN (1991: 122)-, incide en exceso en la personalización de los candidatos como si fuesen celebrities, o retrata lo sensacional o inusual en detrimento de la política real y sus programas (LiCHTER et al.,1999).

7 En un sentido similar, DE LARA et al. $(2011$ : 13, 21) diferencian entre cuatro tipos de autorreferencia en televisión: cuando el programa alude a sí mismo, a otros programas de la cadena; a la cadena en términos generales, y, por último, a otras cadenas de la misma empresa televisiva o a otros medios del mismo grupo de comunicación. 
A efectos de valoración crítica del quehacer profesional, nos resulta mucho más sugestiva la distinción entre autorreferencia, o alusión al propio medio o al conglomerado mediático de pertenencia o a sus integrantes, y heterorreferencia, o menciones a medios, soportes o grupos comunicacionales de la competencia con los que el medio no tiene ningún vínculo empresarial. Esta última categorización apunta a que la metacobertura no resulta nunca una práctica desideologizada, sino que suele portar valores positivos en el caso de la autorreferencia y negativos en la heterorreferencia (SANTín, 2009: 85-87, 153), como posteriormente examinaremos.

A este respecto interesa retomar a Esser y D'ANGelo $(2003,2006)$ cuando diferencian entre tres tipos frames metacomunicacionales dentro del enfoque centrado en la propia labor del periodismo (o press frame): canalización (conduit), estrategia (strategy) y responsabilidad (accountability). Si bien su análisis se circunscribe nuevamente al ámbito de la comunicación política, la clasificación resulta útil para otras prácticas, dado que la canalización da cuenta, de forma neutra, del papel que juegan los medios como diseminadores de información política -ej. cuando un periódico alude a la declaración de un candidato en una cadena de televisión-, la estrategia, cuando el medio asume implícitamente que juicio un papel relevante, con independencia de emitir un juicio sobre este rol -ej. el relato de la función de un medio en un debate electoral-, y la responsabilidad, cuando el medio trabaja asumiendo los valores éticos y (auto) regulatorios de la profesión periodística -ej. noticias orientadas a educar a la audiencia acerca de la construcción mediática de cualquier campaña electoral-. Adaptando estos esquemas, podríamos hablar pues de auto o heterorreferencia neutra, reflexiva o normativa, y, en este sentido, distinguir su carácter absoluto -del medio a sí mismo- o relativo -a otros medios o contenidos del mismo grupo-, y determinar su transparencia o invisibilidad (véase figura 1). De esta manera estaremos avanzando en la dirección marcada por estudios que reclaman pasar del análisis "de la estereotipia referencial de los medios a la ontología y axiología mediática que fundan" (MonDElo y GAITÁN, 2002); o, en otras palabras, del examen de los "referentes mediáticos (tematización y jerarquía) como valores sociales, al estudio de los objetos, aconteceres y valores comunicacionales (discursos éticos y morales) como los referentes del propio acontecer social" (PIÑUEL y GAITÁn, 2010) ${ }^{8}$.

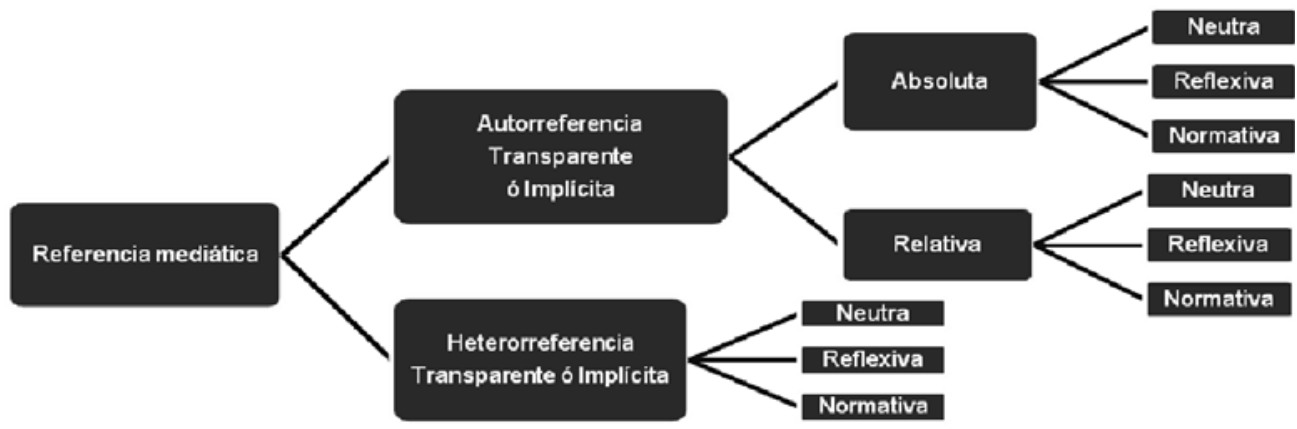

Fig. 1. Los valores de la referencia mediática. Elaboración propia

8 Esto mismo es compartido por DE LARA et al. (2011: 26), que consideran que hasta el momento "el interés del investigador se ha volcado: 1) bien sobre los géneros, los formatos y 


\section{Balance de los estudios en España}

Más allá de los estudios emprendidos en el ámbito anglosajón, en España se percibe un interés incipiente por esta materia, si bien los trabajos siguen siendo escasos, han tenido escasa continuidad en el tiempo y, en su mayoría, abordan tangencial o parcialmente el fenómeno, especialmente en el caso de la televisión y, en menor medida, la publicidad (BARRera, 1999; Costa, 2005; Huici, 1991; GonZÁlez OÑATE y FANJuL, 1999; GonZÁlez ReQuenA, 1989; IMBERT, 2003, 2011; LóPEZ Font y GONZÁlez Oñate, 2005; Mondelo y Gaitán, 2002; Paniagua, 2002; Rodríguez Ferrándiz, 2005; Tous, 2009).

Con carácter más específico, la investigación pionera de Marina SANTín (2006, 2007, 2009) se centra en el análisis de la información autorreferencial en las secciones de Sociedad, Cultura, Comunicación y Espectáculos en tres cabeceras nacionales de referencia: El País, El Mundo y $A B C^{9}$, al objeto de evaluar los criterios periodísticos implícitos en estas prácticas. Los contenidos metacomunicacionales no son, a decir de la autora, un problema en sí mismos. El inconveniente surge cuando dejan de servir a intereses puramente informativos para trabajar al servicio de fines autopromocionales y comerciales hasta difuminar la frontera entre información y publicidad. A decir de la investigadora, los medios tienden a hablar mal de la competencia, pero bien de sí mismos -de sus premios, promociones, índices de audiencia o difusión, etc.${ }^{10}$ (SANTín, 2009: 85-87, 153), creando un sistema desvirtuado de valor noticia: "Las informaciones que hacen referencia a los medios de la competencia tienen unos niveles de noticiabilidad más altos que las informaciones en las que únicamente informan sobre ellos mismos. Lo cual indica que cuando informan sólo sobre ellos o las empresas de su grupo esas informaciones carecen en numerosas ocasiones de los requisitos que se exige que tenga un acontecimiento para ser valorado como noticia". Para ello utilizan estrategias discursivas como la confusión de géneros -o la preeminencia del informativo-, la inserción en secciones distintas a la propia de la comunicación, o la elaboración de falsas piezas informativas sin firma, muchas veces elaboradas por el propio departamento de marketing de las empresas mediáticas. Desafortunadamente la autorreferencia casi nunca se emplea para dar a conocer a la ciudadanía la trastienda de los medios; a saber, cuestiones referentes a la composición e intereses del grupo de comunicación, rutinas profesionales o reconocimiento de los errores que inevitablemente atañen a la práctica periodística.

los contenidos de la prensa o de los programas de la radio y la TV, es decir, sobre aspectos contenidistas (CARLÓN, 2006) o, si queremos, con más atención sobre la dimensión semántica que sobre la sintáctica y la pragmática (RODRÍGUEZ FERRÁNDIZ: 2001); 2) bien sobre la publicidad insertada en prensa radio y televisión".

9 La autora desarrolla para ello un análisis de contenido de 612 artículos de periódicos de temática autorreferencial, seleccionados mediante técnicas de muestreo aleatorio simple entre 1990 y 2002.

10 Las temáticas autorreferenciales más habituales son en este orden: información acerca de suplementos, entregas de premios y celebraciones, promociones de los diarios, encuentros y conferencias en las que participa el medio, presentación de libros y datos sobre medición y difusión de audiencias (SANTín, 2006: 203-205). 
Por otro lado, el grupo Mediación Dialéctica de la Comunicación Social (MDCS) de la Universidad Complutense de Madrid ha explorado la autorreferencia desde una perspectiva gnoseológica que sitúa a los medios como constructores de conocimiento $\mathrm{y}$, en último término, de realidad social. Si la búsqueda de la verdad ${ }^{11}$ es el ideal al que debe tender toda praxis periodística, los resultados de un análisis de contenido de los siete periódicos nacionales de mayor tirada revelan un abuso de la autorreferencia con fines muy alejados de todo sentido de la responsabilidad pública ${ }^{12}$. En los relatos periodísticos autorreferenciales, presentes en todas las secciones del periódico, vuelve a predominar el género informativo y la noticia frente a la interpretación o la opinión, así como modalidades existenciales del discurso -o aquellas en las que el medio apela a lo que sucede o acontece-, a cierta distancia, por ejemplo, de las epistémicas -vinculadas al saber o no conocer acerca de un asunto-. Por otra parte, el predominio de claves de sentido de tipo evaluativo -o discursos que refieren a lo que se dice en el universo mediático-, frente a un discurso minoritario en clave normativa o empírica -o aquellos que hablan bien sobre lo que se hace o bien sobre lo que realmente acontece${ }^{13}$, se suma al hecho de que el relato circular se cifra además en clave metonímica, puesto que "una gran parte de esas referencias no se refieren al orbe mediático en su totalidad sino, de forma privilegiada, a aquella parte del mismo que pertenece al grupo empresarial, medios o programas [...] en que se inscribe el discurso" (PIÑUEL y GAITÁN, 2010) ${ }^{14}$. Todo ello da cuenta de un ejercicio egótico y poco autorreflexivo en el que los periódicos se perfilan como conformadores de un acontecer real y terminado, más que mediático y, por ende, mediado.

${ }^{11}$ Recogida en el Artículo 20 de la Constitución Española de 1978, como reclaman los autores.

12 Los autores se basan, entre otros, en un análisis de contenido de 1476 artículos de prensa de carácter autorreferente, en tres sondas, durante cuatro semanas seguidas elegidas al azar en el bienio 2008-2009 en las siete cabeceras: El País, El Mundo, ABC, La Razón, La Vanguardia, El Correo y La Voz de Galicia.

13 Si tenemos en cuenta que el estatuto normativo de la profesión se suele definir cada vez más en torno a juicios gremiales acerca de la labor propia y ajena -frente a las normas o reglamentos escritos universalmente vinculantes-, resulta llamativo que los discursos mayoritarios acerca de lo que se dice (evaluativos) están fuertemente centrados en regulaciones socialmente comprometidas y que, en cambio, los enunciados de tipo empírico -en torno a lo que acontece en el universo mediático- aparecen, en su mayoría, sin episteme. Este hecho lleva a los autores a denunciar una consecuencia descaminada en el ejercicio del periodismo, en la línea de los trabajos de Putnam y HaBermas (2008): el tránsito desde la elusión de normas demasiado constrictivas y universales -juicios en torno a la verdad o falsedad de los hechos- hacia el relativismo absoluto de los valores evaluados en torno a las virtudes atribuidas, muchas veces interesadamente, a los usos y prácticas de los diversos actores profesionales (Piñuel y Gaitán, 2010).

14 Como se puede comprobar, las conclusiones de SANTín y el MDCS coinciden en algunos puntos: valoración sobredimensionada del self frente al retrato o interpretación de la realidad extramediática, construcción del relato autorreferente en clave de acontecer verdadero -hegemonía del género informativo, inserción en las diversas secciones del periódico-, etc. 
Otra interesante línea de investigación es la que emprende Alicia De LARA y otros colaboradores analizando el carácter autorreferencial o autopromocional de espacios o tiempos tanto en prensa (De LARA, 2010) como en radio (SÁnChez Olmos et al., 2011) y televisión (De LARA et al., 2011). En este último, que recoge conclusiones de los anteriores, además de detectar una presencia masiva en todos los medios $(11)^{15}$, los autores denuncian que la autopublicidad explícita en formatos publicitarios declarados (house ads) se refuerza a base de alusiones implícitas y encubiertas insertas en toda la programación y que atañen tanto al propio medio como a otros del mismo grupo empresarial, a fin de crear sinergias -o autopublicidad intermedial-. Si bien referencia y autorreferencia no son valores absolutos sino cuestiones de grado de las que ningún mensaje -mediático o no- puede sustraerse, su abuso apunta a una reducción de tiempo -radio y televisión- o espacio -prensa- dedicado a representar realidades extra-mediáticas, desempeño ideal esencial de los medios, en pro de referenciar al propio medio -el medio en el mensaje ${ }^{16}$-, con objetivos promocionales o incluso como estrategia misma de continuidad: "rellenar páginas o minutos de programación de los que se han fugado los anunciantes de pago o que cuesta mucho completar con producción de contenidos originales" ${ }^{17}$.

Por último, María Luisa Humanes (2009), desde una perspectiva inspirada en los estudios electorales descritos en el epígrafe anterior (EsSER y D' ANGELo, 2006), evalúa las interacciones entre medios, relaciones públicas y políticos en la meta-cobertura de las elecciones generales de 2004. A partir del análisis de contenido de El País, ABC y $E l M u n d o^{18}$, HUMANES comprueba un predominio del frame centrado en describir las estrategias de propaganda de partidos políticos y asesores (publicity) frente al énfasis en la propia labor de la prensa (press), que, a diferencia de otros contextos como el estadounidense aún no parece haber adquirido entidad propia. Una de las conclusiones colaterales del estudio interesa a efectos comparativos con las investigaciones antes descritas: El frame metacomunicacional se aplica de nuevo de forma privilegiada para legitimar el mensaje del candidato o partido más afecto al medio y deslegitimar el del contrario -ej. El País utiliza enfoques centrados en temas y programa político en el caso del PSOE e incide, en cambio, en las estrategias electoralistas cuando relata al PP; viceversa en el caso de El Mundo- (HuMANES, 2009: 125).

15 En este trabajo, en base a un análisis de contenido de 24 horas de programación de tres cadenas generalistas, incluyendo a Antena 3, el 14 de abril de 2011, los autores denuncian excesos tales como el del $20 \%$ de programación autorreferencial de Telecinco o casi el 10\% en una TVE que en la actualidad ha dejado de depender de la publicidad.

16 Según la acertada paráfrasis a McLuhan que da título al trabajo.

17 Además de, por supuesto, vulnerar la ley que exige que los contenidos publicitarios televisivos deben estar perceptiblemente diferenciados.

18 La investigadora parte del análisis de contenido de 620 piezas informativas de las secciones y suplementos dedicados a la campaña electoral en estos medios. 


\section{Conclusiones}

Lo autorreferencial es constitutivo de la lógica interna de los medios y la comunicación misma, puesto que, si recordamos a $\operatorname{HABERMAS}(1997,1998)$, en el lenguaje humano residen criterios universales de validez que activamos siempre que formulamos actos de habla o enunciados sobre el mundo con objeto de comprendernos. Sin embargo, la práctica autorreferencial de los medios aún está lejos de alcanzar valores como la verdad o la justicia mediante un consenso intersubjetivo en el que los agentes -medios y corporaciones- constituyan o refuercen estos mismos criterios -o situación ideal de habla-19.

En su exceso, la autorreferencia tiende más a la creación de pseudo-acontecimientos que fantasean, magnifican e incluso retuercen la realidad hasta acabar con los significados mismos de lo real, en la lógica determinada por los clásicos del simulacro (BAudrillard, Virilio, Debord). Si la meta-comunicación es un vehículo central para activar prácticas autorreflexivas que a la vez den cuenta del propio carácter mediado de cualquier mensaje, los resultados hasta ahora descritos apuntan justamente a lo contario. El discurso autorreferente se emplea más bien para reforzar la sinergia entre los diferentes medios y empresas, de modo autopromocional, o incluso como estrategia misma de continuidad, alejada de todo compromiso con la información veraz y de la senda reductora de la complejidad apuntada por LUHMANN.

Por otra parte, si tenemos en cuenta que los valores éticos que rigen la praxis profesional se definen cada vez más, no tanto por normas o reglamentos escritos, sino por juicios en el seno de la propia profesión acerca, por ejemplo, de la facultad o virtud de los comunicadores, resulta problemático el desigual reparto de estas atribuciones, "más abundantes y reconocibles entre los nuestros y más carenciales o discutibles entre los que pertenecen a otros grupos mediáticos" (PIÑUEL y GAITÁN, 2010).

En su lógica de confundir información y publicidad, realidad y pseudoacontecimiento parece que el periodismo occidental lleva a la exasperación los valores narcisistas que conforman la fisonomía de una cultura postmoderna, por lo demás marcada por un capitalismo también turboalimentado (LUTTWAK, 2000, en ZALLo, 2011: 54), ajeno a toda regulación y sumido en la lógica del lucro, la privatización y la concentración crecientes, o en la acertada expresión que da título al trabajo de PÜHRINGER y SIEGERT (2007): There's no business without show-business.

Con la autorreferencia entramos pues en el paradójico territorio de la autorreverencia -el periodismo egocéntrico-, el narcisismo -el periodismo ensimismado- y circular -el periodismo tautológico-, que magnifica y pocas veces reflexiona acerca de su papel central en la construcción social de la realidad y redundante en exceso del interés del periodista y sus empresas, cuando no del de las redes clientelares que lo determinan: grupos de interés político, económico, financiero. Entre tanto, la sociedad

${ }^{19}$ Y que atañen, entre otros, a la verdad -que nuestros juicios sean verificables-, rectitud -adecuados a normas aceptadas por la comunidad-, veracidad -que el enunciado sea creíble y honesto en su planteamiento- y el entendimiento -que sea competente lingüísticamente- (HABERMAS, 1998). 
se deja de lado, falta de significados reales, y sumida en un patológico desorden cognitivo que le impide distinguir entre acontecer social y acontecimiento pura e interesadamente mediático.

\section{Referencias bibliográficas}

ABRIL, Gonzalo (2005): Teoría general de la información. Datos, relatos y ritos. Madrid, Cátedra.

BAUDRILLARD, Jean (1984): Cultura y simulacro. Barcelona, Kairós.

BAUDRILLARD, Jean (1996): El crimen perfecto. Barcelona: Anagrama.

BAYM, Geoffrey (2005): "The Daily Show: discursive integration and the reinvention of political journalism". Political Communication, no 22, pp. 259-276.

BARRERA, Carlos (1999): "La batalla digital española o los medios mediatizados", en RODRÍGUEZ Andrés, ROBERTO y SÁDABA, Teresa (eds.): Periodistas ante conflictos. El papel de los medios de comunicación en situaciones de crisis. Pamplona, Universidad de Navarra, pp. 207-240.

BECK, Ulrich (2006): La sociedad del riesgo. Hacia una nueva modernidad. Paidós, Barcelona. [ $1^{\text {a }}$ Ed. 1986]

BREWER, Paul R. y MARQUARDT, Emily (2007): "Mock news and democracy: analyzing The Daily Show". Atlantic Journal of Communication, vol. 15, $\mathrm{n}^{\circ}$ 4, pp. 249-67.

CARLÓN, Mario (2006): De lo cinematográfico a lo televisivo. Buenos Aires, La Crujía.

COSTA, Joan (2005): Identidad televisiva en 4D. Barcelona, Grupo Design.

CHOMSKY, Noam y HERMAN, Edward S. (2000): Los guardianes de la libertad. Propaganda, desinformación y consenso en los medios de comunicación de masas. Barcelona, Crítica. [1ª Ed. 1981]

D'ANGELO, Paul (1999): "Framing the press: A new approach to assessing the cynical nature of press self-coverage and its implications for information processing". International Communication Association Congress, San Francisco.

D'ANGELO, Paul (2002). "News framing as a multiparadigmatic research program: A response to Entman". Journal of Communication, $n^{\circ}$ 52, pp. 870-888.

DEACON, David; GOLDING, Peter y BILLIG, Michael (2001): "Press and broadcasting: 'real issues' and real coverage", en NORRIS, Pippa (ed.): Britain votes 2001. Oxford, Oxford University Press, pp. 103-114.

DE LARA, Alicia (2010): "El problema del autobombo en el diario impreso". Miguel Hernández Communication Journal, $\mathrm{n}^{\circ}$ 1, pp. 132-152.

DE LARA, Alicia; RODRÍGUEZ FERRÁNDIZ, Raúl y SÁNCHEZ OLMOS, Cande (2011): "El medio en el mensaje (I): La autorreferencia en la televisión generalista". En Actas del III Congreso Internacional Latina de Comunicación Social, 29 pp. 
DIMITROVA, Daniela V. et al. (2005): "War on the web. The immediate news framing of the Gulf War II". The International Journal of Press/Politics, vol. 10, $\mathrm{n}^{\circ} 1$, pp. 22-44.

DOTRAS, Ana María (1994): La novela española de metaficción. Gijón, Júcar.

DUNNE, Michael (1992): Metapop: Self-referentiality in contemporary American popular culture. Jackson y Londres, University Press of Mississippi.

HUMANES, María Luisa (2009): "Nuevos temas noticiosos en las elecciones generales de 2004. La presencia de metacobertura en la prensa española". Zer, vol. 14, $\mathrm{n}^{\mathrm{o}} 26$, pp. 105-128.

ECO, Umberto (1975): Apocalipticos e integrados ante la cultura de masas. Barcelona, Lumen.

ECO, Umberto (1986): “TV: La transparencia perdida”, en La estrategia de la ilusión. Barcelona, Lumen, pp. 220-223.

ENTMAN, Robert (1993): "Framing: Toward clarification of a fractured paradigm". Journal of Communication, vol. 43, $\mathrm{n}^{\circ}$ 4, pp. 51-58.

ESSER, Frank (2009): "Metacoverage of mediated wars: How the press framed the role of the news media and of military news management in the Iraq wars of 1991 and 2003". American Behavioral Scientist, vol. 52, n 5, pp. 709-734.

ESSER, Frank y D'ANGELO, Paul (2003): "Framing the press and the publicity process: A content analysis of metacoverage in Campaign 2000 Network News". American Behavioral Scientist, vol. 46, n 5, pp. 615-641.

ESSER, Frank y D'ANGELO, Paul (2006): "Framing the press and the publicity process in German, British, and U.S. General Elections. A comparative study of metacoverage". Harvard International Journal of Press/Politics, vol. 11, n 3, pp. 44-66.

FOUCAULT, Michel (1998): Las palabras y las cosas: una arqueología de las ciencias humanas. Buenos Aires, Siglo XXI. [1 ${ }^{\text {a }}$ Ed. 1966]

GITLIN, Todd (1991): "Blips, bytes, and savvy talk: Television's impact on American politics". En DAHLGREN, Paul y SPARKS, Colin (eds.): Communication and citizenship. Boston, Routledge, pp. 119-136.

GONZÁLEZ OÑATE, Cristina y FANJUL, Carlos (2009): "Marcas televisivas. La gestión de la continuidad en el medio televisivo español". Revista Latina de Comunicación Social, nº 64, pp. 894-908.

GONZÁLEZ REQUENA, Jesús (1989): El discurso televisivo: espectáculo de la posmodernidad. Madrid, Cátedra.

HABERMAS, Jürgen (1997): Teoría de la acción comunicativa. Crítica de la razón funcionalista. Vol. 2. Madrid, Taurus. [1 $\left.{ }^{\mathrm{a}} \mathrm{Ed} .1981\right]$

HABERMAS, Jürgen (1998): Facticidad y validez. Madrid, Trotta.

HUICI, Adrián (1991): "La autorreferencia en el discurso publicitario". Comunicación y sociedad, vol. $4, \mathrm{n}^{\circ} 1$ y 2 , pp. 139-146. 
IMBERT, Gérard (2003): El zoo visual. De la televisión espectacular a la televisión especular. Barcelona, Gedisa.

IMBERT, Gérard (2011): La sociedad informe. Post-modernidad, ambivalencia y juego con los límites. Madrid, Icaria.

JAY, Paul (1984): Being the text: Self-representation from Wordsworth to Roland Barthes. Ithaca, NY, Cornell University Press.

JOHNSON, Thomas J.; BOUDREAU, Timothy y GLOWAKI, Chris (1996): “Turning the spotlight inward: How leading news organizations covered the media in the 1992 presidential election". Journalism and Mass Communication Quarterly, vol. 73, no 3, pp. 657-671.

KERBEL, Matthew R. (1998): Edited for television: $C N N, A B C$, and American Presidential Elections. Oxford, Westview Press.

KERBEL, Matthew R. (1999): Remote and controlled: Media politics in a cynical age. Boulder, CO, Westview.

KERBEL, Matthew R.; APEE, Sumaiya y ROSS, Marc H. (2000): "PBS ain't so different: Public broadcasting, election frames, and democratic empowerment". The Harvard International Journal of Press/ Politics, vol. 5, nº 4, pp. 8-32.

LASCH, Christopher (1999): La cultura del narcisismo. Barcelona, Andrés Bello.

LASH, Scott (2005): Crítica de la información. Buenos Aires y Madrid, Amorrortu.

LICHTER, Robert y NOYEW, Richard E. (1995): Good intentions make bad news. Lanham, MD, Rowman \& Littlefield.

LICHTER, Robert S.; NOYES, Richard E. y KAID, Linda L. (1999): "No news or negative news: How the networks nixed the '96 Campaign". En KAID, Linda L. y BYSTROM, Dianne G. (eds.): The electronic election: Perspectives on the 1996 Campaign Communication. Mahwah, NJ, Lawrence Erlbaum, pp. 3-13.

LÓPEZ FONT, Lorena y GONZÁLEZ OÑATE, Cristina (2005): "El posicionamiento en 20": las autopromociones en las cadenas de televisión". Revista Comunicar, vol. XIII, n ${ }^{\circ} 25,8$ pp.

LIPOVETSKY, Gilles (2003): La era del vacio. Ensayo sobre el individualismo contemporáneo. Barcelona, Anagrama.

LOZANO, Carlos; PIÑUEL, José Luis y GAITÁN, Juan Antonio (2011): “Las verdades implantadas en los titulares de prensa sobre los temas de comunicación. Análisis de la construcción de discursos hegemónicos a partir de las auto-referencias hacia la comunicación”. Razón y Palabra, n 74, 24 pp.

LUHMANN, Niklas (2000): The reality of mass media. Stanford, Stanford University Press.

MANOVICH, Lev (2005): El lenguaje de los nuevos medios de comunicación. Barcelona, Paidós. 
MIGUEL DE BUSTOS, Juan Carlos (2000): "Industrias culturales: gratuidad y precios en Internet". Zer, no 9, pp. 115-150.

MISSIKA, Jean Louis (2006): La fin de la télévision. París, Seuil

MONDELO, Edisa y GAITÁN, Juan Antonio (2002): "La función social de la televerdad". Telos, Cuadernos de Comunicación, Tecnología y Sociedad, n 53, pp. 35-43.

NÖTH, Winfried (2001): "Autorreferencialidad en la crisis de la modernidad". Cuadernos: Revista de la Facultad de Humanidades y Ciencias Sociales, Universidad Nacional de Jujuy, San Salvador de Jujuy, Argentina, nº 17, pp. 365-369.

NÖTH, Winfried y BISHARA, Nina (eds.) (2007): Self reference in the media. Berlin, Mouton de Gruyter.

OLSON, Scott R. (1987): "Meta-television: popular postmodernism”. Critical Studies in Mass Communication, $\mathrm{n}^{\mathrm{o}}$ 4, pp. 284-300.

PANIAGUA, Pedro (2002): La prensa escrita ante la televisión privada: tratamiento de la aparición de Tele-5 en los medios impresos. Madrid, Servicio de Publicaciones de la Universidad Complutense. - Tesis doctoral

PÉREZ BOWIE, José Antonio (2006): "El cine en, desde y sobre el cine: metaficción, reflexividad e intertextualidad en la pantalla". Anthropos. "Metaliteratura y metaficción. Balance crítico y perspectivas comparadas", n² 208, pp. 122-137.

PIÑUEL, José Luis y GAITÁN, Juan Antonio (2010): "El discurso hegemónico sobre la verdad y la comunicación en la autorreferencia mediática en Prensa". Revista Latina de Comunicación Social, $\mathrm{n}^{\circ}$ 65, pp. 572-594.

PÜHRINGER, Karin y SIEGERT, Gabriele (2007): "There's no business without show-business: Self-reference as self-promotion". En NÖTH, Winfried y BISHARA, Nina (eds.): Self reference in the media. Berlin, Mouton de Gruyter.

PUIG, Luis y TALENS, Jenaro (1999): Las culturas del rock. Valencia, Pretextos.

RODRÍGUEZ FERRÁNDIZ, Raúl (2005), "No disparen sobre el periodista: egolatría y dolor en el discurso de la información". Diálogos de la Comunicación, $\mathrm{n}^{\mathrm{o}}$ 71, pp. 76-85.

SÁNCHEZ OLMOS, Cande; RODRÍGUEZ FERRÁNDIZ, Raúl y DE LARA, Alicia (2011): "El medio en el mensaje: autorreferencia en radio". I Congreso Internacional de Comunicación Audiovisual y Publicidad "The radio is dead. Long live the radio". Bilbao, 24-25 noviembre.

SANTÍN, Marina (2006): "La autorreferencia como estrategia de promoción: Periodismo o publicidad". Zer, nº 20, pp. 197-209.

SANTÍN, Marina (2007): "El protagonismo de los medios en los diarios: El problema de la autorreferencia". Global Media Journal en Español, vol. 4, nº 7, pp. 18-30.

SANTÍN, Marina (2009): La autorreferencia en la prensa. La cobertura informativa de los acontecimientos propios. Madrid, Dykinson. 
STAM, Robert (1992): Reflexivity in Film and Literature: From Don Quixote to JeanLuc Godard. New York, Columbia University Press.

STEMPEL, Guido y WINDHAUSER, John (1991) (eds.): The media in the 1984 and 1988 Presidential Campaigns. New York, Greenwood.

TOUS, Ana (2009): "Paleotelevisión, neotelevisión y metatelevisión en las series dramáticas americanas". Revista Comunicar, vol. XVII, n 33, pp. 175-183.

VIRILIO, Paul (1988): Estética de la desaparición. Madrid, Anagrama.

WILLIAMS, Daron B. (2009): Fun with frames: Exploring metacommunication and real media frames in South Park's fake news. Tesis de maestría no publicada. Virginia Polytechnic Institute and State University.

WILLIAMS, Paul (2004): Media narcissism and self-reflective reporting: metacommunication in televised news broadcasts and web coverage of operation Iraqui freedom. Tesis doctoral no publicada. University of Florida.

WILLIAMS, Raymond (2011): Televisión. Tecnología y forma cultural. Buenos Aires, Paidós. [1 ${ }^{\mathrm{a}}$ Ed. 1977]

WOLF, Mauro (1997): "Los emisores de noticias en la investigación sobre comunicación". Zer, n 3, pp. 9-14.

ZALLO, Ramón (2011): Estructuras de la comunicación y de la cultura. Políticas para la era digital. Barcelona, Gedisa. 